\title{
Variation of Compressive Strength of Fresh and Precast Concrete in 3 Years in Sulfate
}

\author{
Xiaoxu Yu ${ }^{1,2, a}$, Jingshu Zhang ${ }^{1,2, b, *}$, Xinmian $\mathrm{Li}^{2,3, c}$, Qingyou Dong ${ }^{2,4, d}$ and Yinhua Zhang ${ }^{2,5, c}$ \\ ${ }^{1}$ Key Laboratory of Mechanics on Disaster and Environment in Western China of the Ministry of Education, \\ Lanzhou University,South Tianshui Road, 222, Lanzhou, China \\ ${ }^{2}$ School of Civil Engineering and Mechanics, Lanzhou University, South Tianshui Road, \\ 222, Lanzhou, China. \\ ${ }^{3}$ Gansu Henglu Traffic Investigation Design Co.,Ltd., Taolin Road, 1, Lanzhou, China \\ ${ }^{4}$ Shanghai Zhongfang Architectural Design Co., Ltd., Zhonghua Road, 1600, Shanghai, China \\ ${ }^{5}$ Gansu Architectural Design and Research Institute, Jingning Road, 81, Lanzhou, China \\ a yuxx15@lzu.edu.cn, bjshzhang@lzu.edu.cn, c270521558@qq.com, ${ }^{\text {d } 512192870 @ q q . c o m, ~}$ \\ e343340822@qq.com \\ *corresponding author
}

Keywords: fresh concrete, precast concrete, immersion test, $\mathrm{Na}_{2} \mathrm{SO}_{4}$ solution, variation of comprehensive compressive strength, proportion of fly ash

\begin{abstract}
We conducted an immersion test for fresh and precast concrete in $\mathrm{Na}_{2} \mathrm{SO}_{4}$ solution of 5 $\mathrm{g} / \mathrm{L}$ over 3 years. The water-to-binder ratio is 0.50 and the proportions of fly ash are $0-35 \%$. The descent rate of compressive strength curve is regarded as the criterion, and the conclusions are as follows: (1) For corroded concrete, the compressive strength has a dividing point between strengthening phase and damage phase. The dividing point of precast concrete is $540-720 \mathrm{~d}$, and is not related to content of fly ash. The dividing point of fresh concrete is $180-720 \mathrm{~d}$, and is further delayed with an increase in content of fly ash. (2) The optimum value of fly ash for both fresh and precast concrete is $25 \%$. (3) For non-corroded concrete, fly ash decreases the compressive strength before 180 days, and increases in a given time interval of 270-720d, but over long durations, the compressive strength is approximately the same regardless of fly ash content. (4) The sulfate corrosion resistance of precast concrete is higher than that of fresh concrete.
\end{abstract}

\section{Introduction}

When the groundwater and soil contain higher concentrations of $\mathrm{SO}_{4}{ }^{2-}$, concrete structures in direct contact with them are vulnerable to corrosion before the period of setting and hardening. This problem is essentially corrosion of fresh concrete. However, few studies have been conducted on the corrosion resistance of fresh concrete.

In 2011, Wang ${ }^{[1]}$ designed the test whose age lasted for 270d. Owing to the short test age of this test, the compressive strength decreased very little or did not decrease at late age. Therefore, the variation of the compressive strength of corroded concrete and the differences between the corrosion resistance of fresh concrete and precast concrete could not be clearly obtained.

Since the first batch of tests failed to reach a clear conclusion during 270d. In 2013, Dong et al ${ }^{[2]}$ performed the second batch of tests by prolonging the test age to 1080d.

Sum up, this paper analyzes the data of second batches of 1080d. Based on the descent rate of the compressive strength curve, the determination of the sulfate corrosion resistance of fresh and precast concrete is obtained. The variation of compressive strength of fresh and precast concrete over $1080 \mathrm{~d}$, as well as the influence of fly ash on variation of compressive strength, is analyzed. 


\section{Experimental Program}

\subsection{Test Materials and Mix Proportions}

The cement and rank II fly ash are from the paper ${ }^{[3]}$. We used a particle-size gradation of 5-16 $\mathrm{mm}$ gravel as the coarse aggregate. Sand with a fineness modulus of 2.98 was used as the fine aggregate. We used anhydrous sodium sulfate powder as the corrosive medium and used running water as the mixing water. And precast conditions are given in Table 1.

\subsection{Specimen Preparation and Test Methods}

We used a full-immersion test in the experiment. The $\mathrm{Na}_{2} \mathrm{SO}_{4}$ solution was replaced every $60 \mathrm{~d}$ during the test to maintain a constant concentration. And the concrete cubes were divided into three groups, given in Table 2 .

We adopted nine test exposure times (table 3) and tested the compressive strength at the end of each time and took the average as the compressive strength.

For precast concrete, the concrete specimens were cured for 30 days before immersion. Therefore, the actual age of these specimens was 30d older than the test ages.

\section{Analysis and Discussion}

\subsection{Test Materials and Mix Proportions Variation of Compressive Strength of Non-corroded Concrete}

The strengths of fresh and precast concrete are reported in Table 3.

The strength values for concrete cubes of side length $10 \mathrm{~cm}$, multiplied by $0.76^{[4]}$, are converted to values for concrete cylinders $(\varphi 15 \times 30 \mathrm{~cm})$,

Data on the strength development of non-corroded concrete (type P-W) with or without fly ash are shown in Fig.1.

Fig. 1 indicates that less strength is observed in concrete with fly ash than in concrete without fly ash at an early stage, and that the strength in concrete with fly ash increases more rapidly than the strength of concrete without fly ash at the same stage and the difference between their strength constantly decreases. Concrete with fly ash has fewer cement hydration products than concrete with fly ash because the fly ash replaces some of the cement clinker before 30d.Therefore, the strength of concrete with fly ash increases more quickly. Fig. 1 also shows that the group FA35 concrete is the weakest among the four groups of concrete before 180 days, and is the strongest in the time interval of 270-720d.

\subsection{Variation of Compressive Strength of Corroded Fresh and Precast Concrete}

\subsubsection{The Effect of Test Age on Corroded Fresh and Precast Concrete}

Compressive strength development of fresh and precast concrete with different proportions of fly ash is plotted in Fig.2 and Fig.3.

It is evident from Figs.2-3 that the strength of concrete initially increases with increasing age, but subsequently decreases with increasing age. The possible reasons for the observed behaviour of concrete are as follows. At the early age, the concrete pores are filled with the swelling ettringite and gypsum ${ }^{[5]}$, making the concrete denser and reinforcing its strength, which is the strengthening phase. At a late age, concrete porosity is relatively lower, and the continuous formation can't be accommodated ${ }^{[6]}$. An expansive force leads to the cracking of concrete and the enlargement and transfixion of these cracks ${ }^{[7]}$, which is the damage phase.

The time, when the strength curves in Figs. 2-3 reach the maximum value, is taken as a reference value used to investigate the strength development of corroded fresh and precast concrete. In Table 3 , for precast concrete, the dividing time between the strengthening phase and the damage phase is between 540 and $720 \mathrm{~d}$ in the precast concrete, and this time is not related to the content of fly ash. 
In Figs. 2-3, the initiation time of corrosion for fresh concrete is between 180 and 720d, which begin to be delayed as the content of fly ash increases.

\subsubsection{The effect of fly ash on corroded fresh and precast concrete}

Fig. 2 shows that before 180 days, the strength of precast concrete with fly ash is greater than that of concrete without fly ash, except that group FA25 and group FA35 are slightly weaker than group FA0 at 30 days. This is different from non-corroded concrete. The density of concrete with fly ash is less than the density of concrete without fly ash at an early age, which leads to greater infiltration. The strengthening action of sulfate increases the strength of the concrete, and the effect of this increase on the strength of concrete is greater than that of the reduction on strength by fly ash at the early stage ${ }^{[8]}$.

However, Fig.3 shows that the strength of fresh concrete with fly ash is less than the strength of concrete without fly ash before 180 days. Fresh concrete has not been fully hardened at an early age, and it is less compact than precast concrete. Little difference exists in the amount of Na2SO4 infiltrating the fresh concrete with different fly ash content. Therefore, fresh concrete with fly ash is not as strong as concrete without fly ash because of the inhibition of fly ash on the sulfate reaction.

Fig. 3 indicates that adding fly ash obviously can improve the corrosion resistance of fresh concrete. The descent rate of strength in group FA25 is the smallest of the three groups of concrete with fly ash at 900-1080d. But the concrete in group FA25 showed greater corrosion resistance.

It is evident from Fig.2 that each group of concrete has entered the damage phase, and the difference in permeability is slight and little difference in strength among each group of concrete is seen after 900d. Thereafter, the descent rate of strength curves after $900 \mathrm{~d}$ is used to judge the influence of fly ash on the corrosion resistance of concrete.

The descent rate of the strength curve is defined as the ratio of the difference between the strength of concrete at 1080 and $900 \mathrm{~d}$ to the difference in time at 1080d and 900d, given in Table 4.

It is evident from Table 4 that the descent rate of the strength curve for concrete with fly ash is much smaller than that for concrete without fly ash. This finding indicates that the blending of fly ash has increased the corrosion resistance of precast concrete. And the precast concrete with a blend of $25 \%$ fly ash has the smallest descent rate and the greatest level of corrosion resistance.

The content of fly ash in concrete helps improve the sulfate corrosion resistance of fresh and precast concrete, and the fly ash has an optimum value. The strength of concrete increases along with an increasing amount of fly ash up to an optimum value, beyond which strength starts to decrease with the addition of any more fly ash.

\subsubsection{Corroded fresh and precast concrete}

Strength development of non-corroded concrete, corroded fresh concrete, and precast concrete with different fly ash content are shown in Figs.4-7.

Fig.4 illustrates that for concrete without fly ash, it reaches a maximum value at $900 \mathrm{~d}$ and reduces by $7.7 \mathrm{MPa}$ at $1080 \mathrm{~d}$, a decrease of only $11.34 \%$. The concrete in type P-N is stronger than the concrete in type F-N after 720d. Hence, precast concrete without fly ash is more resistant to $\mathrm{Na}_{2} \mathrm{SO}_{4}$ attack compared with fresh concrete without fly ash.

It can be seen from Figs.4-7 that the strength of all fresh and precast concrete in sulfate shows a descending trend after $900 \mathrm{~d}$. Although the strength curve has a single data point after $900 \mathrm{~d}$, it is reliable for analysis of corrosion resistance by age for 900-1080d. Therefore, the corrosion resistance of concrete thus can be judged by comparing the descent rate of strength curves at 9001080d for each type of concrete.

Table 5 shows the descent rate of the strength curves at 900-1080d of concrete in type P-N is smaller than that of concrete in type F-N. Hence, concrete with fly ash in type P-N is more resistant to the attack than that in type F-N.

Precast concrete cured for 28d has low porosity and has reached a relatively dense state. The penetration of sulfate solutions begins on the outside and moves slowly inward, and corrosion occurs only in concrete of a certain thickness from the surface to the interior. As cracks increase, sulfate solutions permeate into concrete and gradually corrode it ${ }^{[9]}$. 
The porosity of fresh concrete is lower than that of precast concrete at the same stage, and the pore size distribution of fresh concrete is more uniform. Thus, fresh concrete is stronger than precast concrete during the strengthening phase before 720d. After entering the damage phase, the cracks in fresh concrete develop more quickly than that in precast concrete after 900d. And the strength of fresh concrete decreases more rapidly than that of precast concrete after $900 \mathrm{~d}$.

Therefore, precast concrete with $28 \mathrm{~d}$ of curing is more resistant to sulfate than fresh concrete.

\section{Conclusion}

The following conclusions are drawn:

1. For corroded fresh and precast concrete, the compressive strength of concrete can be divided into the strengthening phase and the damage phase along with an increase in the test age. The dividing point of precast concrete is between 540 and $720 \mathrm{~d}$, and it is not related to the content of fly ash. The dividing point of fresh concrete is between 180 and $720 \mathrm{~d}$, and it is further delayed with an increase in the content of fly ash.

2. For corroded fresh and precast concrete, substituting a certain amount of fly ash for cement of the same weight helps to improve the sulfate corrosion resistance. The amount of fly ash has an optimum value. In this study, the optimum value of fly ash for both the fresh and precast concrete is $25 \%$.

3. For non-corroded concrete, fly ash decreases the compressive strength at an early age before $180 \mathrm{~d}$, and increases the compressive strength in a given time interval of 270 to $720 \mathrm{~d}$, but over long durations, the compressive strength is approximately the same regardless of fly ash content.

4. The sulfate corrosion resistance of precast concrete is higher than that of fresh concrete.

\section{Acknowledgements}

This experiment is supported by The Natural Science Foundation of China (project approval number: 51678283).

Table 1 Mix proportions of concrete

\begin{tabular}{cccccc}
\hline Mix & $\begin{array}{c}\text { Cement } \\
(\mathrm{kg})\end{array}$ & $\begin{array}{c}\text { Water } \\
(\mathrm{kg})\end{array}$ & $\begin{array}{c}\text { Fine aggregate } \\
(\mathrm{kg})\end{array}$ & $\begin{array}{c}\text { Coarse } \\
\text { aggregate }(\mathrm{kg})\end{array}$ & Fly ash $(\mathrm{kg}, \%)$ \\
\hline FA0 & 420 & 210 & 584 & 1186 & 0,0 \\
FA20 & 336 & 210 & 584 & 1186 & 84,20 \\
FA25 & 315 & 210 & 584 & 1186 & 105,25 \\
FA35 & 273 & 210 & 584 & 1186 & 147,35 \\
\hline
\end{tabular}

Table 2 Mixing and curing conditions

\begin{tabular}{cccc}
\hline Designation & $\begin{array}{c}\text { Water used } \\
\text { for mixing }\end{array}$ & $\begin{array}{c}\text { Water used } \\
\text { for curing }\end{array}$ & Simulated scenario \\
\hline P-W & $\begin{array}{c}\text { Ordinary } \\
\text { water }\end{array}$ & Ordinary water & $\begin{array}{c}\text { Precast-Water } \\
\text { Controlled concrete } \\
\text { cubes }\end{array}$ \\
\hline F-N & $\begin{array}{c}\text { Na2SO4 } \\
\text { solution of 5 } \\
\text { g/L }\end{array}$ & $\begin{array}{c}\text { Immersed in Na2SO4 solution of 5 g/L } \\
\text { together with mold for 12 h, and cured } \\
\text { with the same solution immediately } \\
\text { after demolding. }\end{array}$ & $\begin{array}{c}\text { Fresh-Na2SO4 } \\
\text { Concrete cubes } \\
\text { reflecting fresh } \\
\text { conditions }\end{array}$ \\
\hline P-N & Ordinary & $\begin{array}{c}\text { Initially cured in ordinary water for 28 } \\
\text { days, and subsequently cured with } \\
\text { Na2SO4 solution of 5 g/L. }\end{array}$ & $\begin{array}{c}\text { Precast-Na2SO4 } \\
\text { Concrete cubes } \\
\text { reflecting precast } \\
\text { situations }\end{array}$ \\
\hline
\end{tabular}


Table 3 Compressive strengths of concrete specimens for each test age (MPa)

\begin{tabular}{lllllllllll}
\hline \multirow{2}{*}{$\begin{array}{c}\text { Mixing and } \begin{array}{c}\text { curing } \\
\text { conditions }\end{array} \\
\text { proporti } \\
\text { ons }\end{array}$} & 30d & 90d & 180d & 270d & 360d & $540 \mathrm{~d}$ & $720 \mathrm{~d}$ & 900d & $108 \mathrm{~d}$ \\
\hline \multirow{4}{*}{ P-W } & FA0 & 50.0 & 52.6 & 58.4 & 60.3 & 61.6 & 62.0 & 64.0 & 65.5 & 67.5 \\
& FA20 & 41.3 & 48.8 & 61.7 & 63.2 & 65.0 & 64.8 & 62.5 & 65.7 & 67.5 \\
& FA25 & 43.8 & 47.3 & 55.3 & 61.5 & 64.2 & 67.3 & 66.1 & 64.6 & 66.1 \\
& FA35 & 34.7 & 43.3 & 54.9 & 66.3 & 68.2 & 68.6 & 66.0 & 64.0 & 66.4 \\
\hline \multirow{4}{*}{ F-N } & FA0 & 67.0 & 72.0 & 80.2 & 69.0 & 67.8 & 64.2 & 62.4 & 55.8 & 50.8 \\
& FA20 & 63.0 & 70.2 & 79.9 & 80.9 & $/$ & 77.0 & 77.6 & 74.9 & 64.4 \\
& FA25 & 58.3 & 71.7 & 72.1 & 74.7 & 75.1 & 82.8 & 88.4 & 77.8 & 72.0 \\
& FA35 & 52.9 & 59.1 & 69.2 & 77.6 & $/$ & 78.2 & 81.6 & 70.8 & 62.7 \\
\hline \multirow{4}{*}{ P-N } & FA0 & 50.4 & 52.9 & 58.4 & 60.6 & 61.0 & 64.0 & 67.2 & 67.9 & 60.2 \\
& FA20 & 53.7 & 59.3 & 62.0 & 62.9 & 66.2 & 67.5 & 65.8 & 58.6 & 57.1 \\
& FA25 & 48.1 & 56.4 & 61.2 & 65.8 & 64.7 & 64.3 & 64.3 & 60.2 & 58.8 \\
& FA35 & 49.3 & 59.0 & 64.5 & 64.7 & 65.8 & 67.3 & 69.4 & 64.9 & 61.9 \\
\hline
\end{tabular}

Note: The forward slash (/) indicates that the discreteness is excessive, and hence the data were abandoned.

Table 4 The descent rate of strength curves in 900-1080d of type P-N (*100\%)

\begin{tabular}{|c|c|c|c|c|}
\hline descent rate mix proportions & FA0 & FA20 & FA25 & FA35 \\
\hline descent rate $(* 100)$ & 4.28 & 0.83 & 0.78 & 1.67 \\
\hline
\end{tabular}

Table 5 The descent rate (*100\%) in type F-N and type P-N

\begin{tabular}{lllll}
\hline P-N(F-N) & FA20 & FA25 & FA35 \\
\hline F-N & Descent rate & 5.83 & 3.22 & 4.50 \\
\hline P-N & Descent rate & 0.83 & 0.78 & 1.67 \\
\hline
\end{tabular}

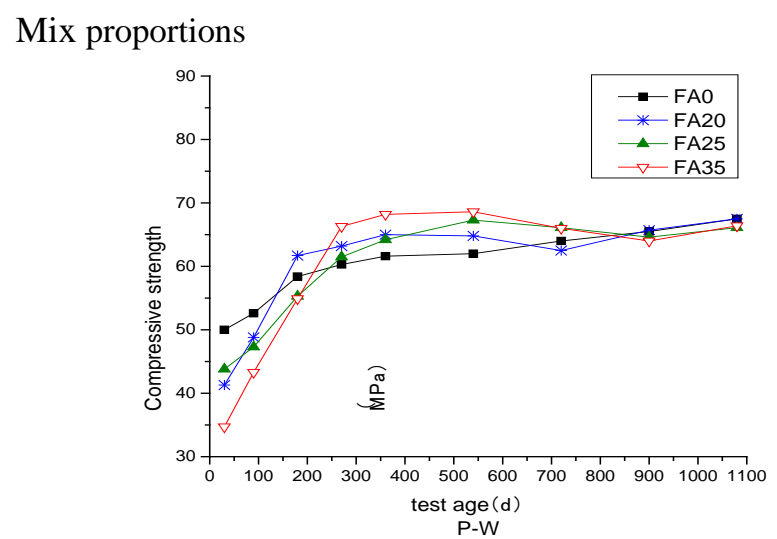

Fig 1 Strength development of different mix proportions of type P-W 


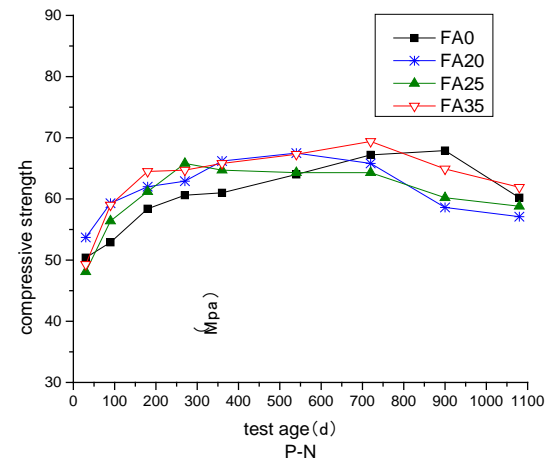

Fig 2 Strength development of different mix proportions of type P-N

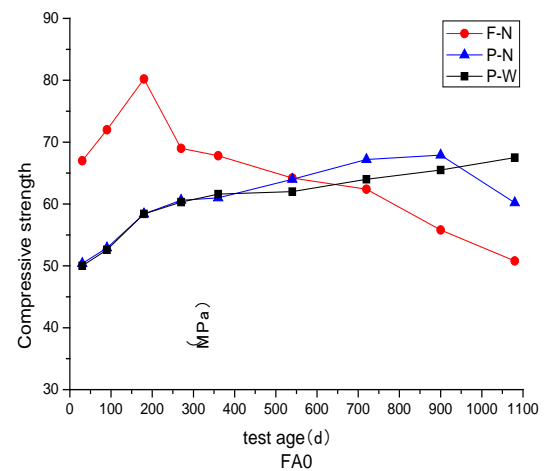

Fig 4 Strength development of different mixing and curing conditions of group FA0

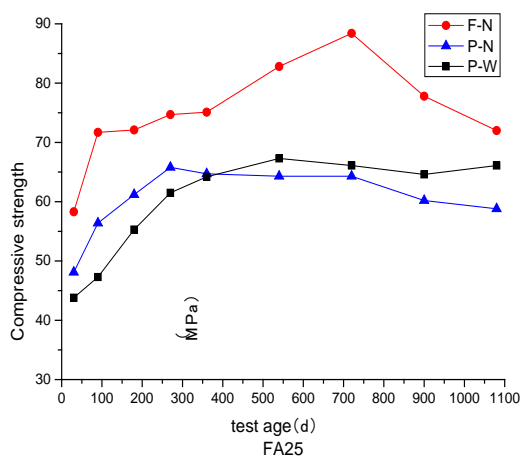

Fig 6 Strength development of different mixing and curing conditions of group FA25.

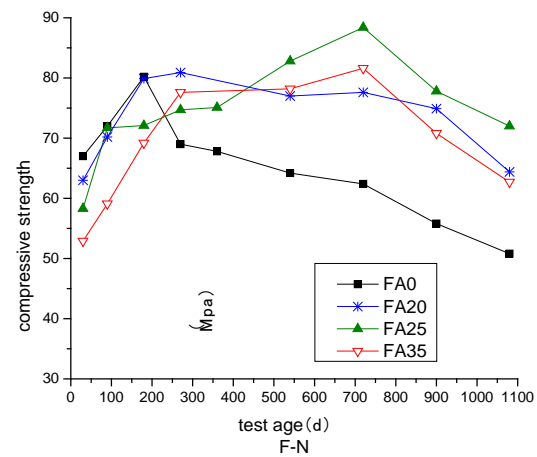

Fig 3 Strength development of different mix proportions of type F-N

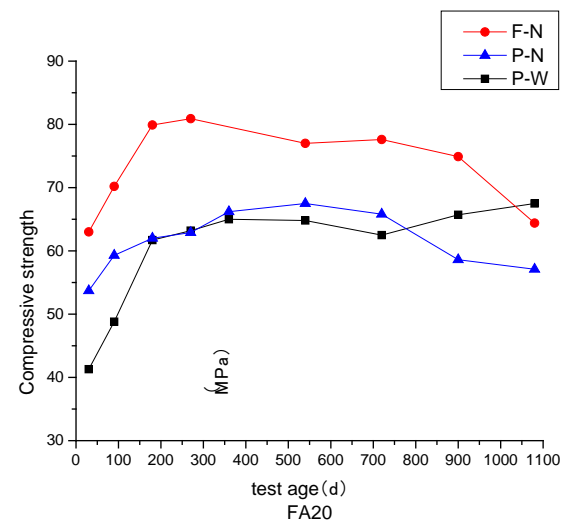

Fig 5 Strength development of different mixing and curing conditions of group FA20

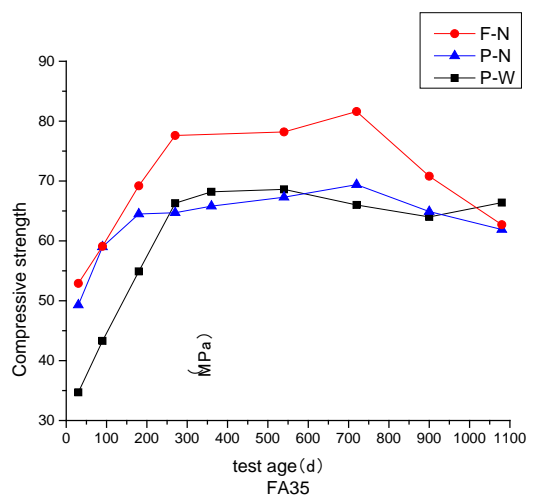

Fig 7 Strength development of different mixing and curing conditions of group FA35.

\section{References}

[1] Wang Chao-cheng. Adaptability Experimental research of the filling pile in strong sulfate corrosive Environment [D]. Lanzhou: Lanzhou University, 2011. (in Chinese)

[2] Dong Qing-you. Experimental research of sulfate corrosion resistance of fresh concrete [D]. Lanzhou: Lanzhou University, 2013. (in Chinese)

[3] Zhang Jing-shu, Zhang Yin-hua, Feng Li-ping, et al. Damage model of fresh concrete in sulphate environment [J]. Journal of Central South University, 2015, 22(3): 1104-1113.

[4] Chinese Standard for Test Method of mechanical properties on ordinary concrete (in Chinese). 
[5] Al-Amoudi O S B. Attack on plain and blended cements exposed to aggressive sulfate environments[J]. Cement and Concrete Composites, 2002, 24(3): 305-316.

[6] Santhanam M, Cohen M D, Olek J. Effects of gypsum formation on the performance of cement mortars during external sulfate attack [J]. Cement and Concrete Research, 2003, 33(3): 325-332.

[7] Santhanam M, Cohen M D, Olek J. Mechanism of sulfate attack: a fresh look part 2, proposed mechanisms [J]. Cement and Concrete Research, 2003, 33(3): 341-346.

[8] Q. Jueshi, S. Caijun, W. Zhi, Activation of blended cements containing fly ash [J]. Cement and Concrete Research, 2001, 31(8): 1121-1127.

[9] Santhanam M, Cohen M D, Olek J. Mechanism of sulfate attack: a fresh look part 1, summary of experimental results [J]. Cement and Concrete Research, 2002, 32(6): 915-921. 